Authors have nothing to disclose with regard to commercial support.

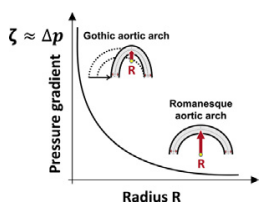

\section{NATURE IS THE BEST}

To the Editor:

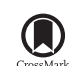

I enjoyed reading the article "How Successful Is Successful? Aortic Arch Shape After Successful Aortic Coarctation Repair Correlates With Left Ventricular Function," by Bruse and colleagues, ${ }^{1}$ showing by magnetic resonance imaging that the Gothic arch shape after aortic coarctation repair correlates with impaired left ventricular function. Itatani and colleagues ${ }^{2}$ recently reported that a smooth aortic arch angle reduces energy loss after the Norwood procedure. Agnoletti and colleagues ${ }^{3}$ found that a sharp angulation of the aortic arch is associated with early pulse-wave reflection and increases augmentation pressure after the Lecompte technique for repair of transposition of the great arteries. These 3 examples nicely demonstrate that a steep arch angle may impair blood flow hemodynamics with a negative effect on left ventricular function in the long term. The results reflect a basic concept in nature: decreasing the radius of an arch from a Romanesque shape toward a Gothic shape increases the resistance factor (Figure 1) and thereby the pressure gradient $\Delta \mathrm{p}$, which correlates with left ventricular afterload, as shown in the following formula: $\Delta \mathrm{p}=\zeta \times \mathrm{Q} / 2 \times \bar{\omega}^{2} \quad(\zeta$ resistance factor, $\mathrm{Q}$ density of blood, $\omega$ blood flow velocity).

There are several factors explaining the impaired hemodynamics and increased energy loss associated with a Gothic aortic arch shape, including friction loss, secondary streamlines, wave reflections, and flow detachment. This is even more pronounced in a knee-like aortic arch shape. There is now growing evidence that this energy loss may have a negative effect on left ventricular function. ${ }^{1}$ Therefore, it should be the aim, if ever possible, to achieve the normal Romanesque shape of the aortic arch during surgery, which is not easy in the Norwood operation or coarctation repair, but is possible during the arterial switch operation in transposition of the great arteries using the direct spiral

The Editor welcomes submissions for possible publication in the Letters to the Editor section that consist of commentary on an article published in the Journal or other relevant issues. Authors should: • Include no more than 500 words of text, three authors, and five references. • Type with double-spacing. $\bullet$ See http://jtcs.ctsnetjournals.org/ misc/ifora.shtml for detailed submission instructions. • Submit the letter electronically via jtcvs.editorialmanager.com. Letters commenting on an article published in the JTCVS will be considered if they are received within 6 weeks of the time the article was published. Authors of the article being commented on will be given an opportunity of offer a timely response ( 2 weeks) to the letter. Authors of letters will be notified that the letter has been received. Unpublished letters cannot be returned.

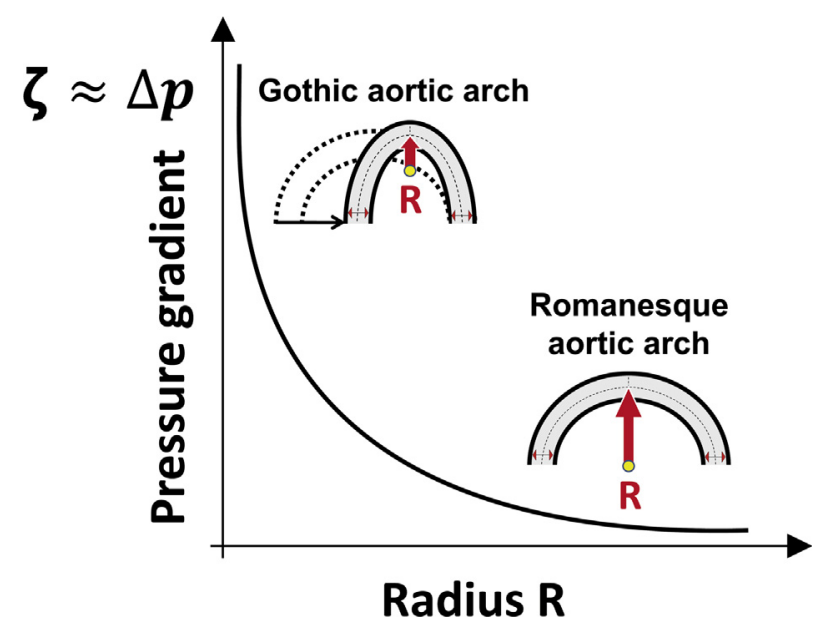

FIGURE 1. Principle relationship between radius $(R)$ of arch shape and resistance factor $(\zeta)$. If the radius decreases from a Romanesque arch shape to a Gothic arch shape (black arrow), the resistance factor increases and thereby the pressure gradient (see formula in text).

anastomosis. ${ }^{4,5}$ It took millions of years for nature to create the physiologic Romanesque-shaped aortic arch as the optimal solution for that particular purpose with the least burden for adjacent structures over an expected life span of 80 years or more for the children from today. Therefore, we should try to imitate nature as much as possible: Nature is the best.

Hans-Hinrich Sievers, $M D^{a}$ Carsten Rickers, $M D^{b}$

${ }^{a}$ Department of Cardiac and Thoracic Vascular Surgery University Medical Center Schleswig-Holstein

Campus Lübeck Lübeck, Germany

${ }^{b}$ Department of Congenital Heart Disease and Pediatric Cardiology University Medical Center Schleswig-Holstein Campus Kiel Kiel, Germany

\section{References}

1. Bruse JL, Khushnood A, McLeod K, Biglino G, Sermesant M, Pennec X, et al. How successful is successful? Aortic arch shape after successful aortic coarctation repair correlates with left ventricular function. J Thorac Cardiovasc Surg. 2017; 153:418-27.

2. Itatani K, Miyaji K, Qian Y, Liu JL, Miyakoshi T, Murakami A, et al. Influence of surgical arch reconstruction methods on single ventricle workload in the Norwood procedure. J Thorac Cardiovasc Surg. 2012;144:130-8.

3. Agnoletti G, Ou P, Celermajer DS, Boudjemline Y, Marini D, Bonnet D, et al. Acute angulation of the aortic arch predisposes a patient to ascending aortic dilatation and aortic regurgitation late after the arterial switch operation for transposition of the great arteries. J Thorac Cardiovasc Surg. 2008;135:568-72.

4. Rickers C, Kheradvar A, Sievers HH, Falahatpisheh A, Wegner P, Gabbert D, et al. Is the Lecompte technique the last word on transposition of the great arteries repair for all patients? A magnetic resonance imaging study including a spiral technique two decades postoperatively. Interact Cardiovasc Thorac Surg. 2016;22:817-25. 
5. Sievers HH, Kheradvar A, Kramer HH, Rickers C. 3D heart model and 4D flow MRI 20 years after spiral arterial switch operation. Thorac Cardiovasc Surg Rep. 2016;5:44-6.

http://dx.doi.org/10.1016/j.jtcvs.2017.04.016

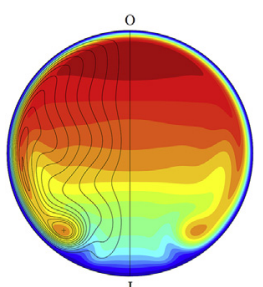

\section{WHY ARCH CURVATURE AFFECTS ARCH RESISTANCE \\ Reply to the Editor:}

The commentary by Sievers and Rickers ${ }^{1}$ of Bruse and colleagues, ${ }^{2}$ study of arch anatomy in coarctation is well taken. As they point out, the shape of the confined flow region influences the appearance and magnitude of friction loss, secondary streamlines, wave reflections, and flow separation, all resulting in energy loss and increased ventricular afterload. The authors allude to the overall "diameter of curvature" (call it "D") of the arch as a single metric governing such effects. Although arch anatomy and its hemodynamic effects are more complicated than that, there is, in fact, a simple argument in which D appears as the sole metric governing friction loss, as follows:

Imagine a thin straight tube in which there exists steady (nonpulsatile) flow. We know from elementary fluid dynamics that the resistance, $R_{p}$, through such a conduit is given by Poiseuille's Law,

$$
\mathrm{R}_{\mathrm{p}}=(128 / \pi) \times\left(\mathrm{ul} / \mathrm{d}^{4}\right)
$$

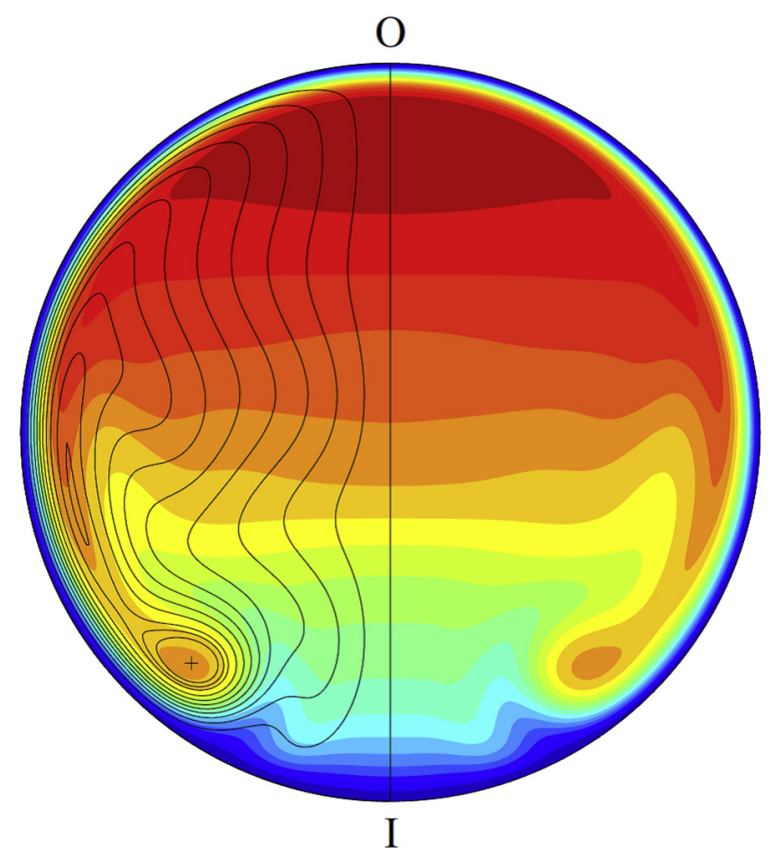

FIGURE 1. Axial flow velocity field in a curved tube. Blue = low velocity, $I=$ lesser curvature.
Author has nothing to disclose with regard to commercial support.

Where $\mathrm{u}$ is kinematic viscosity, $\mathrm{l}$ is the tube length, and $\mathrm{d}$ is tube diameter. Now imagine wrapping this tube into a circle, so the two ends almost meet. Does the resistance of flow through the tube change? The answer is yes. Fundamental to understanding this is the fact that resistance in steady flow is due to friction loss caused by adjacent "layers" of fluid flowing at different velocities and thus rubbing against each other. This is called "shear." The friction, proportional to viscosity, slows the fluid down, which is interpreted as resistance to flow. In a straight tube, most of the shear occurs near the wall of the conduit. In a curved tube, the fluid flow is more complex, because the fluid has an additional, centripetal force acting on it. The flow pattern is one of circular vortices interposed on ambient axial flow (so-called toroidal flow) (Figure 1). The more complex flow results in more shear occurring throughout the cross-section of the flow, thus more friction, that is, resistance. Under certain conditions, the new resistance, $\mathrm{R}_{\mathrm{d}}$, can be expressed semi-empirically in terms of the usual Poiseuille's resistance as

$$
\mathrm{R}_{\mathrm{d}}=\mathrm{R}_{\mathrm{p}} \times\left[0.37 \mathrm{De}^{0.36}\right]
$$

where De is called the "Dean number" and is equal to the Reynolds number times the square root of the ratio, $d / D$, of tube diameter to diameter of curvature. ${ }^{3}$ For typical values of the infant aortic arch, arch curvature results in flow resistance that is 1.5 to 2.0 times what it would be if the arch were a straight tube. Furthermore, the sharper the turn in the aortic arch (ie, the smaller the value of $D$ ), the larger $R_{d}$ becomes. This is resistance against which the ventricle must work to eject.

With pulsatile flow, other phenomena such as wave propagation and reflection come into play. ${ }^{4}$ In the real patient aortic arch, with its branches, the calculation of resistance or, more accurately, impedance, as a function of shape essentially requires the use of computational fluid dynamics.

William M. DeCampli, MD, PhD

The Heart Center

Arnold Palmer Hospital for Children

Department of Clinical Sciences

College of Medicine

University of Central Florida

Orlando, Fla 